psychiatrist than Professor Anthony Clare who has agreed to take on the job of Public Education Director following this year's annual general meeting. Let us hope that this public identification with the College will do something to mitigate the stigma of being a psychiatrist which Dr McKenzie and I both deplore.

BRICE PITT, Chairman, Public Education Committee, Royal College of Psychiatrists

\section{Patients not clients - a community survey among elderly patients}

Sir: May I congratulate Drs Upton, Boer and Neale on their survey on how psychiatric inpatients wished to be called (Psychiatric Bulletin. March 1994, 18, 142-143).

A complementary enquiry among elderly patients (over the age of 65) and their carers in the community shows a similar trend. Out of 16 patients attending the day hospital one wanted to be called a client, one wished to be addressed by her surname, and the rest wished to be called patients. Among 20 patients visited at home by community psychiatric nurses, 18 wished to be called patients, one saw himself as a service user and one as a client. When carers attending the Alzheimer's Disease support group were approached, they wished their 111 relative to be called a patient in 15 cases out of 18 and 3 out of 18 saw the sufferer as a person with a problem. None of the questioned patients or carers chose the term customer or consumer.

Clearly the commercial jargon in the NHS has not received much support among patients in the community.

Eva CYBULSKA, Stone House Hospital, Thameslink NHS Trust, Cotton Lane, Dartford, Kent DA2 6AU

\section{Delegation of section 5(2) Mental Health Act 1983}

Sir: Crichton \& Townsend (Psychiatric Bulletin. March 1994, 18, 176) draw attention to an important source of uncertainty for junior doctors, the delegation of powers under section 5(2) of the Mental Health Act 1983. As the authors point out, the Code of Practice (HMSO, 1993) suggests that only consultant psychiatrists should nominate deputies. In practice confusion arises when an inexperienced junior doctor in a non-psychiatric specialty is requested to act as deputy.

An additional source of uncertainty is the issue of who is the responstble consultant for the purpose of section 5(2) when a patient on a nonpsychiatric ward is referred to and seen by the junior duty psychiatrist. Paragraph 8.6 of the
Code of Practice seems to indicate that in such a situation, for the purposes of the Mental Health Act, the individual is a 'psychiatric patient' and the (duty) consultant psychiatrist is the responsible doctor.

HMSO (1993) Code of Practice. Mental Health Act 1983. London: HMSO.

RICHARD PRETTYMAN, Queen's Medical Centre, Nottingham NG7 2UH

\section{Home Office Index of Addicts and Regional Databases}

Sir: I read with interest the article by Ghodse, Jones \& Thorley (Psychiatric Bulletin, March $1994,18,169-170$ ) on the value of the database which holds information on drug abusers (and which may become linked to European database). They did not mention its original, still appropriate, function, which was to identify addicts getting supplies from more than one legal source. Unfortunately ever since the Home Office Drugs Branch has kept the data on a computer, the computer has kept going down and when it recovers its health it has residual amnesia. Even when it is functioning at its best it often does not recognise patients whom I know to have a long drug history.

Another fault is that from the start there has been a reliance on the date of birth to spot double scripters - which is naïve and of course known by addicts. Right at the beginning, about 1966, I suggested that recording a simple cheese-bite would be useful. I am sure our dentist colleagues would be able to suggest a way of coding it.

DALE BECKETT, 18 Ockendon Road, Islington, London N1 3NP

Sir: I acknowledge Dr Beckett's point about the function of the Home Office Index, and would like to emphasise that the Regional Substance Misuse Databases have a completely different role. Because they collect information on a voluntary basis from a wide range of agencies, both statutory and non-statutory, about any type of current drug problem, they are able to monitor trends in substance misuse much more comprehensively than the Index (which only deals with dependence on notifiable drugs) and can, therefore, make a valuable contribution to service planning.

The other important difference is the total anonymity of patient records on the Regional Substance Misuse Database. However, to prevent duplication of effort when one individual has to be 'notified' to both systems, the database managers have incorporated the necessary procedures into a single process, so that both 
purposes can be fulfilled without undermining their fundamental differences.

In relation to Dr Beckett's suggestion about identification by 'cheese-bite' it should be remembered that many substance misusers are edentulous by the age of 25-30!

HAMID GHodse, St George's Hospttal Medical School, London SW17 ORE

\section{Health gain among psychiatric patients}

Sir: The point made by Elisabeth Ashbridge and Steven Milne, concerning The Health of the Nation and suicide prevention', (Psychiatric Bulletin, February 1994, 18, 110), is an important one. I would, however, suggest that the main reason that the Department of Health has placed such emphasis on a significant reduction in suicide rates by the year 2000 , is simply that there is a lack of information about what, apart from surviving suicide, constitutes health gain for mentally ill people.

With this in mind, the University of Wales College of Medicine, School of Nursing Studies, has established a major research project throughout Wales, which is designed to measure not only the extent to which mentally ill people who are cared for and treated in the community, experience health gain, but also to assess the nature and composition of health gain.

This study will be replicated in Holland and elsewhere in Europe in order to produce comparative international data. A first report may be expected in January 1995 . While the project will not necessarily serve to reduce suicide rates, it may throw light upon the behaviour characteristics and coping ability of those who commit suicide, compared with those who do not. More notably, it will serve to show that suicide is but one, and not necessarily the most important, aspect of health gain (or loss) among psychiatric patients in the community.

KEITH LITTLER, School of Nursing Studies, University of Wales College of Medicine, Heath Park, Cardiff CF4 4XN

\section{Alternative uses for old hospitals}

Sir: 'The Fire at Long Grove Hospital' (Psychiatric Bulletin, February 1994, 18, 94-95) as reported by Henry Rollin indicts those responsible for the "wanton disregard paid to the security of an historic building" and must raise concerns in many parts of the world where major hospital closures have occurred.

In Western Australia, the first asylum to close did so in 1905, and continued in use for various purposes until now it forms the Fremantle Arts Centre. The Claremont Mental Hospital built in 1905 closed in 1985 . The main core of the buildings has since remained derelict and vandalised. The architect was Charles Grainger, father of Percy, and responsible for many significant public buildings in Perth. Nevertheless $90 \%$ of his work at Claremont has been demolished, and land sold for housing. The government has recently agreed to fund restoration of the main hall and administrative buildings to develop a community centre. Fortunately the building has escaped the fate of Long Grove, but more by chance than design. In 1992 I visited the hospital in England where I trained as a psychiatric registrar in 1967, St John's, Stone, only to find it boarded up and unused.

It seems urgent that, if these buildings are to be preserved, not only as history, but as resources that the community may want to put better alternative uses, then feasible ideas and options need to be considered. This process could be facilitated if evidence exists of successful alternative uses.

Perhaps the loss of Long Grove might stimulate attention to ways of preserving these old buildings, not as mental hospitals, but as civic resources. Collaboration between architects, historians and psychiatrists could be a fruitful alternative to the sad photographs of Long Grove.

Neville F. Hills, Shenton Park Psychiatric Services for the Elderly, 227 Stubbs Terrace, Shenton Park, WA 6008, Australia

\section{'Quality in the Psychotherapy Service'}

Sir: We recently discussed the paper by $F$. Denman (Psychiatric Bulletin, February 1994, $18,80-82$ ) and, while we acknowledge the diffculties inherent in auditing psychiatric practice, and particularly in auditing psychotherapeutic practice, we wish to raise the following concerns.

Our major concern was that while the paper intended to pass as a "scientific analysis". it appeared subjective in the language used to describe the work in which value judgements were expressed. As an example, "sadly four therapists used no definitive interpretations" and "this is a disappointing figure, particularly because the rater's impression from listening to the tapes was that there were many communicative 'misfires' which could profitably have been investigated but which were left to lie". We were given no direct accounts of clinical material which would have helped to anchor the paper in clinical practice and to convince us of the subjective assessment of the raters.

The author seemed to be putting forward criteria by which to judge "good practice in cognitive 